\title{
A Comparative Study of Problem Solving Styles and Mental Health in Male Substance Abusers and Normal Men
}

\author{
Maryam Sharifi ${ }^{1}$, Gholam Hossein Javanmard ${ }^{2}$ \\ ${ }^{1}$ Psychology Department, Science \& Research Branch of Islamic Azad University of Tabriz, Tabriz, Iran \\ ${ }^{2}$ Psychology Department, Payame Noor University (PNU), Tehran, Iran
}

Email address:

maryam.sharifi82@gmail.com (M. Sharifi), javanmardhossein@gmail.com (G. H. Javanmard)

\section{To cite this article:}

Maryam Sharifi, Gholam Hossein Javanmard. A Comparative Study of Problem Solving Styles and Mental Health in Male Substance Abusers and Normal Men. Psychology and Behavioral Sciences. Vol. 6, No. 3, 2017, pp. 36-42. doi: 10.11648/j.pbs.20170603.11

Received: April 6, 2017; Accepted: April 21, 2017; Published: June 19, 2017

\begin{abstract}
The purpose of this research, which has been done on the basis of causal-comparative method, was the comparison of ways of problem-solving and mental health in people suffering from drug abuse and normal people in Maragheh, Iran. In order to do this, 35 men suffering from Substance Abuse Disorder (SUD) and 35 normal men were chosen using purposeful sampling method and via matching the two groups. Then the participants were requested to answer the 28item General Health Questionnaire (GHQ) and the 24-item Cassidy-Long Problem-Solving Questionnaire. Data were analyzed using the technique of multivariate analysis of variance (MANOVA) and SPSS software. Findings showed that the compared groups in problem-solving ways and constructive and unconstructive items and mental health in depression subcomponents had a meaningful difference. The average scores were higher in constructive problem-solving ways in healthy group, and in unconstructive styles in people suffering from drug abuse. Also, the addicted people meaningfully used unconstructive ways of problem-solving more than healthy people. In mental health, the average scores of addicted people in the issues of somatization, anxiety, and social dysfunction were higher than those of healthy group, and in depression, the average scores of healthy people were higher than those of addicted group. Moreover, the addicted people meaningfully reported more signs of somatization and less depression in comparison with the healthy people. Overall, this research showed that using unconstructive styles of problem-solving in people suffering from drug abuse is more common than that of normal people. This necessitates the planning of treatment and rehabilitation interventions for addicted people.
\end{abstract}

Keywords: Problem-Solving Styles, Mental Health, Addiction

\section{Introduction}

Drug use has existed for centuries and is now considered to be a worldwide problem. Substance abuse is known as a biological, psychological and social disease which affects a person's physical and mental health and causes family, occupational, economic and social problems. These problems are considered as serious threats to public health, and play a major role in crime and corruption and impose, directly or indirectly, significant costs on the community [22]. This psychological-social problem is so widespread that many researchers have been studying it, and through comprehensive investigations on various aspects of drug addiction they try to find possible solutions to it. One of the important aspects of drug addiction is vulnerability to the challenges of everyday life. Inefficient coping strategies and inability to resolve problems in life are among the factors that exacerbates the drug addicts' vulnerability [13].

Mental health is an essential requirement for any individual at any time (World Health Organization, 2001). Internal enabling characteristics signify mental health. Exploiting these resources within the individual enables him to continue his adaptive growth despite the adverse conditions and negative circumstances, and maintain his mental health. Problem solving as a cognitive-behavioral technique emphasizes the cognitive and behavioral aspects. Individual problem solving process includes perception and judgment of preferences. In other words, according to the personality type, one of the two cognitive functions (sensing or witnessing) as well as one of the two judgment functions (thinking or feeling) are so important that individuals utilize 
them in the process of problem-solving and decision-making. Sensing is the collecting of facts, while witnessing deals with the possibilities. Thinking weighs the evidence for and against and finally considers the feeling of dealing with other people's feelings [21].

According to the research literature and taking into account that the addicts have imperfect life skills and apply inefficient problem solving methods in dealing with problems in their lives, and considering several studies which have showed the efficiency of problem solving methods and teaching of efficient methods in the prevention of addiction and prevention of relapse after detoxification [19], [14], therefore, it is necessary to study how addicts deal with difficulties, incidents and natural problems of life and what methods they use to solve these problems. After examining the addicts, Schaefer and Brown (1997) concluded that the expectations of these individuals of the consequences of drug abuse play a significant role in using drugs. These expectations include such items as getting rid of painful thoughts and behaviors, relaxation and stress reduction, facilitating social-sexual relations, improving cognitive and perceptual quality, increasing the duration of pleasure and well-being. Some studies suggest that the intention of an individual for drug abuse, at least in the initial phases of use, is affected by their attitudes towards substance abuse [27]. The studies by Daley and Marlatt (1997), Sobell and Sobell (1997) and Gessop (1994) showed that drug addicts have defects in skills necessary to deal with problems, and substance abuse is a familiar way to overcome difficulties and reduce undesirable emotions caused by difficult interpersonal and intrapersonal situations.

When an individual with substance abuse disorder encounters a problem he avoids facing it rather than taking a problem-oriented and radical stance, because he underestimates and considers himself as a doomed-to-befailed entity [42]. It has been reported that there is a significant relationship between poor coping strategies and inappropriate problem-solving techniques in addicts and people with substance abuse disorders [8], [37].

In a study conducted by Marzabadi, Hashemi Zadeh and Shokouhi (2014) on problem solving methods in addicted and normal soldiers, the results showed that the two groups use different methods in problem solving, and the addicted group has a higher mean in terms of helplessness, control, avoidance and lower mean in terms of creativity, confidence, and attitude. The results of a study by Matinnejad, Mousavi and Shams (2001) on problem-solving and thinking styles in addicted and non-addicted individuals show that problemsolving methods and thinking styles of addicts are different from non-addicts namely, creative problem-solving methods in addicts is less than non addicts. According to the findings of a study by Azad, Hashemizadeh and Shokouhi (2014) there is a significant difference between two groups of addicts and non-addicts in terms of problem-solving methods, Their results showed that addicted individuals utilize nonconstructive problem-solving methods (inability to solve the problem, controlling and avoidance method) more than non-addicts. Bahrami, Moazedian and Hosseini (2012) in a study confirmed that teaching of problem-solving and decision-making skills can have a positive impact on reducing drug addicts' attitude and tendency towards dangerous effects of drug use. The results of another study by Abdi (2002) on problem-solving methods in addicts and nonaddicts showed that addicts use nonconstructive problemsolving methods like inability to solve the problem, controlling and avoidance method more than constructive problem-solving methods such as creativity, confidence, and attitude. The results of a research by Saber, Mousavi and Salehi (2011) also showed that drug addicts use unconstructive problem solving methods such as, helplessness, avoiding and controlling against stress and life problems more than constructive problem-solving methods such as creativity, trust and attitude. According to a research by Babapour (2003), individuals who use the constructive problem solving method are in good mental health. Of the sub-scales of problem-solving method, the scales of trust, creativity and attitude have a positive relationship with mental health while there is a negative correlation with the scales of helplessness and control. The findings by Raiesi, Anisi, Yazdi, Zamani and Rashidi (2008) on mental health showed that such mental disorder symptoms as the scales of psychotic, phobia, aggression, anxiety, depression, interpersonal sensitivity are more common in addicts than non-addicted individuals, but there is no significant difference between the two groups in terms of the scales of somatization disorder, obsession and paranoid thoughts. However, despite the considerable research in the field of mental health and problem-solving methods of people suffering from substance abuse, this process has not been investigated seriously in Iran. Hence, this study tries to fill the existing gap in this regard.

\section{Method}

This study is a causal-comparative research conducted in ex-post facto method. The study sample included substance abusers who had referred to outpatient treatment centers for treatment in Maragheh in 2016. Convenience sampling was done in an outpatient substance abuse treatment health center called "new life" in Maragheh. The participants included 35 patients with drug abuse who had not been detoxified at the time of this study, and they were still suffering from drug abuse according to the doctors and test results of the health center. The inclusion criteria were: male gender, age range between 28-31 years old, being educated (the ability to read and write); and exclusion criteria included mental retardation, neurological diseases and chronic physical, mental and neurologic disorders. The comparison group were randomly selected, including 35 normal individuals matched with the first group for age, gender and education.

The collected data were analyzed using descriptive and inferential statistics. In the descriptive part, such descriptive statistics as mean and standard deviation scores of each variable, and in the analytical section multivariate analysis of 
variance (MANOVA) was used in order to test the hypotheses of the research. And to analyze the data, statistical software SPSS-18 was used.

\subsection{8-Item General Health Questionnaire (GHQ)}

General Health Questionnaire (GHQ) is a "screening inventory" based on self-reporting method used in clinical cases with the aim of tracing those who have a mental disorder. This questionnaire measures four subscales including somatic complaint, anxiety, depression and social dysfunction. By 1988, more than 70 percent of the study about the validity of the GHQ was conducted around the world. Also, validity estimates of the GHQ show that the mean sensitivity of the questionnaire is $84 \%$ and mean specificity is $82 \%$ ( $78 \%$ to $85 \%$ ) (Williams and Goldberg, 1987). Yaghoubi (1995) reported the test sensitivity $86 \%$ and specificity $82 \%$. Validity coefficient of the Persian version of 28-item GHQ was estimated using retest method with an interval of 7 to 10 days on a group of 80 patients at a rate of $91 \%$ which is significant at the one-thousandth error level [31]. Yaghoubi (1995) reported that the overall validity coefficient of this test is $88 \%$ and the validity coefficient of the subtests is between $0 / 81$ to $50 \%$. Questions 1 to 7 are related to somatization, questions 8 to 14 to anxiety and insomnia, 15 to 21 to social dysfunction, and questions 22 to 28 are related to depression. In this study, Cronbach's coefficient alphas for questions related to the somatization, anxiety, social dysfunction and depression were 0.848, 0.90, 0.907 and 0.97 respectively.

\subsection{4-Item Problem-Solving Questionnaire of Cassidy \& Lang (1996)}

Problem-solving questionnaire was designed by Long \& Cassidy in 1996. It has 24 items that measure six factors, and the subject responds to each of the items with yes or no answers. These factors include: failure (feeling helpless and unable to act in problematic situations), controlling manner of the problem (external-internal control), creative way (planning versatile solutions), confidence in solving the problem (belief in the power of the individual to solve the problem), method of avoidance (denial of problems rather than dealing with them) and attitudes (tendency to tackle and solve problems) (Clark, Golder and Qyrburn, Translated by Mehdi Kavian, 2007, cited by Edalati, Ashkani and Modarres, 2009). Mohammadi and Sahebi (2001) reported that the reliability of the scale via internal consistency (Cronbach's alpha) is 60\%. In Babapour and Ezhei's review (2002), this factor was equal to 0.77 and validity coefficient was 0.87 (cited by Bakhshipour Roodsari, 2008).

\section{Result}

The mean (Standard Deviation) age of patients with substance abuse disorder was 29.2 (8.8) and the mean for normal subjects was $31(8 / 2)$. In order to match the two groups in terms of age variant, independent t-test was used and the results indicated that the two groups were matched.

Table 1. Descriptive statistics related to problem-solving styles and sub-components of mental health for both groups under study.

\begin{tabular}{lll}
\hline \multirow{2}{*}{ Problem-solving styles } & Non-addicted group & Addicted group \\
\cline { 2 - 3 } & The mean (SD) & The mean (SD) \\
\hline \multirow{2}{*}{ Constructive } & 18.2 & 11.3 \\
& 28.83 & 51.87 \\
Non-constructive & 10.3 & 15.3 \\
& 66.78 & 45.67 \\
Subcomponents of mental health & Non-addicted group & Addicted group \\
& The mean (SD) & The mean (SD) \\
Somatization & $(\mathrm{N}=35)$ & N=35) \\
Anxiety & 15.482 .59 & 16.862 .85 \\
Social dysfunction & 12.884 .17 & 13.113 .86 \\
Depression & 12.663 .38 & 13.913 .74 \\
\hline
\end{tabular}

According to Table 1, the mean and standard deviation of problem solving styles and mental health components in the two groups are significant, and the average scores in constructive problem-solving styles in the control group are higher than the mean of addicted group, and the nonconstructive problem-solving styles in addicts have a higher mean. Also the mean and standard deviation of both groups in mental health sub-components show that the mean scores of addicts in subcomponents of somatization, anxiety and social dysfunction are higher than the control group, though the mean score of depression scale was higher in the control group compared to the addicts.

Table 2. Results of Kolmogorov-Smirnov test for analyzing the normality of distribution of scores in problem-solving styles.

\begin{tabular}{lllll}
\hline Problem solving styles & Group & Statistics & Degree of freedom & Significant level \\
\hline Constructive & Non-addicted & 0.15 & 35 & 0.060 \\
& addicted & 0.146 & 35 & 0.074 \\
Non-constructive & Non-addicted & 0.11 & 35 & 0.319 \\
& addicted & 0.13 & 35 & 0.081 \\
\hline
\end{tabular}

In order to study the normal distribution of scores, the results of Kolmogorov-Smirnov test were evaluated.
According to the table 2, the achieved significant levels show that the distribution of scores of constructive and 
unconstructive problem solving styles in both groups are normal (significant level is greater than 0.05 ).

To test the homogeneity of covariance matrices, Box's test results were examined and the results showed that this assumption was true for groups under study $(\mathrm{F}=1 / 67, \mathrm{P}=$
0/172). Moreover, the results of Levene's equality of variances test showed that in constructive problem-solving styles $\mathrm{F}$ and $\mathrm{P}$ were as follows: $\mathrm{F} 1,68=3 / 06$ and $\mathrm{P}=0 / 085$; and in unconstructive problem solving styles they were: $\mathrm{F} 1,68=0 / 37, \mathrm{P}=0 / 543$.

Table 3. Multiple test results of multivariate analysis of variance (MANOVA) for the effects of group membership.

\begin{tabular}{lllllll}
\hline Eta squared & P & df error & df hypothesis & F & Value & Test Name \\
\hline $55 / 0$ & $001 / 0>$ & 67 & 2 & $44 / 40$ & $55 / 0$ & Pillai's Effect \\
$55 / 0$ & $001 / 0>$ & 67 & 2 & $44 / 40$ & $45 / 0$ & Wilks' Lambda \\
$55 / 0$ & $001 / 0>$ & 67 & 2 & $44 / 40$ & $21 / 1$ & Red Hotelling \\
$55 / 0$ & $001 / 0>$ & 67 & 2 & $44 / 40$ & $21 / 1$ & Greatest root \\
\hline
\end{tabular}

Multiple MANOVA test results in table 3 show that there is a significant difference between the mean scores of both groups in linear combination of problem-solving styles $(\mathrm{P}<0 / 001)$.

Table 4. MANOVA for comparing group means in each of the problem-solving styles.

\begin{tabular}{llllll}
\hline Effect size & & & \multicolumn{3}{c}{ Significance level of F } \\
\hline Problem-solving style & Sum of squares & Degree of freedom & Mean Square & F & Significance level \\
\hline Constructive & $414 / 802$ & 1 & $414 / 802$ & $78 / 69$ & $001 / 0>*$ \\
Non-constructive & $200 / 403$ & 1 & $200 / 403$ & $03 / 29$ & $001 / 0>*$ \\
\hline
\end{tabular}

The data provided in Table 4 and univariate comparisons show that two groups in comparison are significantly different in terms of constructive methods. For this component, $\mathrm{F}$ is 69.8 , eta-squared is 0.51 and significance level is less than 0.001 . Given that the size of significance level is less than 0.05 in table 4 and by considering the mean of constructive problem-solving styles in the control group (18.28) and addicts (11.51), and as shown in table 1, it's inferred that addicts utilize less effective constructive problem-solving styles than non-addicts. Also, the two groups in comparison are significantly different in nonconstructive methods. For this component, F is 29.03, etasquared is 0.299 and significance level is less than 0.001 . Given that the size of significance level is less than 0.05 in table 4 and by considering the mean of non-constructive problem-solving styles in the control group (10.66) and in addicts (15.45), as shown in table 1, it's inferred that addicts' use of non-constructive problem-solving styles was significantly more than non-addicts.

Table 5. Results of Kolmogorov-Smirnov test for analyzing the normality of distribution of scores.

\begin{tabular}{lllll}
\hline Mental health components & Group & Statistic & Degree of freedom & Significance level \\
\hline Somatization & Non-addict & $12 / 0$ & 35 & $200 / 0$ \\
& Addict & $117 / 0$ & 35 & $200 / 0$ \\
Anxiety & Non-addict & $13 / 0$ & 35 & $0190 / 0^{*}$ \\
& Addict & $16 / 0$ & 35 & $053 / 0$ \\
Social dysfunction & Non-addict & $119 / 0$ & 35 & 35 \\
Depression & Addict & $124 / 0$ & 35 & $200 / 0$ \\
& Non-addict & $12 / 0$ & 35 & $200 / 0$ \\
\hline
\end{tabular}

Kolmogorov-Smirnov test results were studied to evaluate the normality of distribution of mental health components (table 5). The obtained significant levels show that mental health components (somatization, anxiety, social dysfunction, and depression) in the groups are normally distributed (significance levels greater of 0.05).

Box's test results were evaluated to test the homogeneity of covariance matrices. The results showed that the assumption is true $(\mathrm{M}=13 / 65, \mathrm{~F}=1 / 28, \mathrm{P}>0 / 05)$. Establishing error variances is another presumption of this test. Levene's test results showed that in the mental health variable with somatization components $(\mathrm{F}=0 / 445, \mathrm{P}>0 / 05)$, anxiety $(\mathrm{F}=0 / 920, \mathrm{P}>0 / 05)$, social dysfunction $(\mathrm{F}=3 / 12, \mathrm{P}$ $=>0 / 05)$, the assumption of homogeneity of variances exists.

Table 6. Test results of MANOVA for the effects of group membership.

\begin{tabular}{lllllll}
\hline Test name & Value & F & df hypothesis & df error & P & Eta squared \\
\hline Pillai's effect & $23 / 0$ & $89 / 4$ & 4 & 65 & $002 / 0$ \\
Wilks' Lambda & $77 / 0$ & $89 / 4$ & 4 & 65 & $002 / 0$ \\
Red hotelling & $30 / 0$ & $89 / 4$ & 4 & 65 & 0 \\
Greatest root & $30 / 0$ & $89 / 4$ & 4 & 65 & $002 / 0$ \\
\hline
\end{tabular}

The results of multivariate analysis of variance in Table 6 show that the difference between mean scores on a linear combination of components of mental health (somatization, anxiety, social dysfunction, and depression) is significant (P <0/01). 
Table 7. Multivariate analysis of variance to compare group means in any of the components of mental health.

\begin{tabular}{|c|c|c|c|c|c|c|}
\hline Mental health components & Sum of squares & Degree of freedom & Mean of squares & $\mathbf{F}$ & Significance level & Effect size \\
\hline Somatization & $9 / 32$ & 1 & $9 / 32$ & $43 / 4$ & $039 / 0^{*}$ & $061 / 0$ \\
\hline Anxiety & $914 / 0$ & 1 & $914 / 0$ & $057 / 0$ & $813 / 0$ & $001 / 0$ \\
\hline Social dysfunction & $66 / 27$ & 1 & $66 / 27$ & $17 / 2$ & $145 / 0$ & $031 / 0$ \\
\hline
\end{tabular}

The information provided in Table 7, and univariate comparisons show that two groups are significantly different in somatization. For this component, the value of $\mathrm{F}$ is 4.43 , eta squared is 0.06 and significance level is less than 0.05 . Considering the mean somatization in the groups of nonaddicts (15.48) and addicts (16.86) in Table 2, the addicts showed significantly more somatic symptoms than nonaddicts. Moreover, the two groups in comparison are significantly different in depression. For this component, the value of $\mathrm{F}$ is 5.01, eta squared is 0.07 and significance level is less than 0.05 . Considering the mean depression in the nonaddicts (12.43) and addicts (8.94) in Table 2, it is witnessed that the addicts showed less depression than non-addicts.

\section{Discussion}

Overall, findings of the study showed that addicts don't utilize appropriate problem-solving strategies when encountering the problems of life and they tend to utilize non-constructive problem-solving styles. The findings of the study by Warren, Stein and Gerlla (2007) confirmed our hypothesis namely, when an individual with substance abuse disorder faces a problem he avoids facing it rather than taking a problem-oriented and radical stance, because he underestimates and considers himself as a doomed-to-befailed entity. In a study by Smith (2004, as cited by Ramesht and Farshad, 2004) it was shown that training life skills considerably contributes to reduction of alcohol drinking and drug abuse in young individuals. Some studies have also shown that training problem solving skills reduces tendency to drug use [20], [29], [7]. In another study, it was reported that there is a significant relationship between addicts and non-addicts in the poor coping strategies and inappropriate problem solving styles [8], [37]. The results of the study by Marzabadi, Hashemizadeh and Shokouhi (2015) are in line with this hypothesis and confirm that there is a difference between addicts and non-addicts in problem-solving styles, and the addicted group has a higher mean in helplessness, control and avoidance and lower mean in terms of creativity, confidence and attitude (positive attitude and a willingness to face the problems) than the other group. Research findings by Matin Nejad and colleagues (2010) showed that addicts use different problem-solving styles than non-addicts namely, addicts use less creative methods than non-addicts. Saber et al. (2011) concluded that drug addicts use such unconstructive problem solving styles as helplessness, avoidance and controlling more than constructive problemsolving styles like creativity, trust and attitude.

Another result of the study showed that there is a significant difference between the two groups in mental health components (somatization, anxiety, social dysfunction and depression), and addicted people show a lower depression scale compared to non-addicts. This means that non-addicts are depressed. Depression is a common mental disorder [12]. This result is somewhat inconsistent with the findings of most of the previous studies in terms of mental health and substance abuse. In most studies, researchers have concluded that addicted individuals have problems in the components of mental health. Meanwhile, many researchers have been studying depression not only because of its relatively high prevalence, but also the harmful consequences, hospitalization and suicide. Several factors may have a role in the incidence and prevalence of depression. Negative life events and low levels of social support are considered as two factors associated with depression. Stress (negative life events) is said to be the chain of events in a person's life for which he doesn't have the sufficient resources to handle. As a result, he experiences psychological conflict [18].

Lukasiewics, Nezu, Blecha, Alissard, Reynaud et al (2008), Chakrun, Dorron and Swendsen (2004) in their researches on drug addiction, conducted many studies about the personality profile and behavior of addicts. These studies considered personality traits as factors that can lead a person towards addiction. Several studies confirmed the relation between negative life events and mental health [4], [18]. Doherwend and Doherwend (1974, as cited by Sarason, Johnson \& Siegley, 1978) believe that it is due to personal characteristics that the effects of stress and negative life events vary from person to person. While some people are severely affected by minor changes in their life, some others do not surrender or show a little reaction even when serious and dramatic events happen. Mental health professionals believe that individuals' responses to stressful events and also the amount of stress are affected by different social and individual factors. Some of the features of the individuals resistant to stressful life events are: tenacity, hopefulness, optimism, sense of coherence, constructive thinking and social support [40], [30], [15]. Bukstein (2000) studied 60 addicts admitted to the hospital for self-esteem, anxiety and locus of control. His results showed that 80 percent of the addicts have a low self-esteem and locus of control, but a high anxiety rate. Fleming and Barry (1998) in their study of 100 addicts at a therapeutic community (50 in experimental group, 50 in control group) came to the conclusion that those who were trained in life skills showed increased self-esteem and declined depression. Miller (1995) also showed that most addicts try to use drugs again due to psychological problems such as depression and anxiety, weak confidence and low self-esteem and will. Amoli (2004) in a study assessed the 
prevalence of disease, mood disorders and anxiety in hospitalized drug addicts and compared them with nonaddicts. The results of this study showed that $3.72 \%$ of addicts met the diagnostic criteria for mood and anxiety disorders and the most common disorders were major depressive disorder $(66 \%)$ and generalized anxiety disorder (12\%). Farjad, Vajdi and Behravesh, (1996) in a study on psycho-social causes of drug addiction showed that addicts were significantly different from non-addict individuals in depression, aggression, anxiety and interpersonal sensitivity. In a study by Raisi et al (2008) on mental health, the symptoms in addicts were more than non-addicts in scales of psychotic, phobia, aggression, anxiety, depression, interpersonal sensitivity. But there was no significant difference between the two groups in the scales of somatic complaint, obsession and paranoid thoughts. The results also showed that there is a significant difference between drug addicts and non-addicts in terms of mental health. The findings of a study by Bahrami et al (2010) suggest that training problem solving and decision-making skills can decrease drug addicts' tendency towards drugs.

\section{Conclusion}

Considering health as a concept influenced by a complex set of biological, psycho-social, cultural, economic, religious, and environmental factors, it should be noted that in this sense, health is no longer a mere concern of medical practitioners but it is something that needs the attention of all social scientists, and particularly psychologists. According to Caravella, Tod, and Brown (2012) the treatment of substance abuse disorders and mental disorders require a sophisticated and professional training, and people encounter numerous challenges during the course of treatment and recovery. Teaching problem solving skills to drug addicts can considerably reduce addicts' positive attitude towards drugs. Therefore, it can be a major step in the prevention, treatment and recurrence of the disease. It can also help many clients to cope with daily stresses via making right decisions when encountering stressors. Also, changing the attitudes of drug addicts can motivate them to quit using drugs. And it will help them and their families to relieve the pressure and anxiety. Teaching problem-solving skills can be used as a preventive strategy to help individuals avoid getting caught into the trap of drug addiction, and it can act as a shield against the tribulations of life and unreasonable requests of others.

\section{Limitations of the Study}

The limitations include: lack of random sampling, small number of subjects, short duration of follow-up, not studying female drug addicts, failing to study the impact of gender variable, the possibility of biased responses from patients due to personal interests, the possibility of impatience and haste in patients responding to study questions.

\section{References}

[1] Abdi, R., (1380). A comparison between drug addicted and non-addicted individuals, psychology master's thesis. Mashhad Ferdowsi University. Faculty of Psychology and Educational Sciences.

[2] Agha Bakhshi, H., (1379). effects of addiction of father on family function. Social Science Quarterly, 10.

[3] Amoli, M., (2004). Creating safe and drug-free schools. Ettelaat Newspaper, No. 23235, Saturday, January first.

[4] Aneshensel, C. S. (1992). Social stress: theory and research. Annual Review of sociology, 18, 15-38.

[5] Azad Marzabadi, E., and Hashemizadeh, S. M., and Shokohi IP., (1393). A comparison between drugs addicted and nonaddicted soldiers in problem-solving methods. Journal of Military Medicine. 16 (2), 69-75.

[6] Babapour K., (1381). The relationship between problem solving, conflict resolution styles and psychological health among students, doctoral thesis, Tarbiat Modarres University, Tehran.

[7] Bagheri, M. and Bahrami Ehsan, H. (1386). The role of life skills training on knowledge and attitudes towards drugs and selfesteem in students. Journal of Addiction Studies, 1 (3), 150-176.

[8] Ball, S. A. (2005). Personality traits, problems and disorders: Clinical applications to substance use disorders. Journal of Research in Personality, 39 (1), 84-102.

[9] Bukstein, O. G. (2000). Descriptive behavior disorders and substance use disorders in adolescence. Journal of psychoactive drugs, 18 (6), 296- 302.

[10] Caravella, K., Tod, L., \& Brown, A-M. (2012). Awareness into action: How communication skills training enhances traditional substance abuse treatment programs. The Journal of Global Drug Policy and Practice, 6, 1-13.

[11] Chakroun, N., Doron, J., \& Swendsen, J. (2004). Substance use, affective problems and personality traits: Test of association models. Journal de L Encephale, 30, 564-569.

[12] Clark, D. A, Beak, A. T., \& Alford, B. A. (1999). Scientific foundations of cognitive theory and therapy of Depression. New York: John Wiley \& sons. 1-35.

[13] Cooper, I. M. Russel, M. Skinner, B. S. Frone, R. M. \& Mudra, P. (1992). Stress and alcohol use: Moderating effects of gender, Copping and alcohol expectancies. Journal of abnormal psychology, vol, 101, 139-152.

[14] Daley, C. \& Marlatt, A. J. H. Lowinson, P. Ruiz, R. B. Millman, \& J. G Langroad (EDS). G. (1997). Relaps prevention in Substance abuse: A comprehensive text book (430-442). Batimor, Maryland: Williams \& Wikins.

[15] Davison, G. C., \& Neal, J. M. (2001). Abnormal psychology. New York: John Wiley \& sous. 190-191.

[16] Farjad, M. H., Vajdi, Z., and Behravesh, H. (1374). Understanding the causes, symptoms and treatment. Tehran: Badr publications.

[17] Fleming, M. F., Barry, K. L. (1998). Addictive disorders. Mosby year book. 
[18] Folkman, S., \& Lazarus, S. (1986). Stress process and depressive symptomatology. Journal of Abnormal psychology, 95, 107-113.

[19] Gossop M. (1994). Drug and alcohol problems: Investigation. In S. I. E. hindsey and G. E. Powell (Eds). The hand book of clinical adult psychology. (413-438). Hondon: Routledge.

[20] Hollifieled, G. (2002). Training residents in problem solving treatment of depression: A pilot feasibility and impact study. Journal of Mental Health Counseling, 36, 4-8.

[21] Jessup, C, M. (2002). Appling psychological type and "gifts differing" to organizational change. Journal of organizational change management 15 (5): 502-511.

[22] Kaplan, H. I., Sadock, B. J., Grebb, J. A., \& Kaplan, H. I. (1994). Kaplan and Sadock's synopsis of psychiatry: Behavorial sciences, clinical psychiatry. Baltimore: Williams \& Wilkins.

[23] Lazarus, R, S., \& Folkman, S. (1984). Stress, coping and adaptation. New York: springer. 33-95.

[24] Lukasiewicz. M., Neveu. X., Blecha. L., Alissard. B, Reynaud. M., \& Gasquet. I. (2008). Cognitive and behavioral effects pathways to substance-related disorder: a structural model approach exploring the influence of temperament, character, and childhood adversity in a national cohort of prisoners. Alcohol and Alcoholism, 43 (3), 287-295.

[25] Marzabadi, E.,; Hashemizadeh, S. M., and Shokohi, P., (1393). Comparing problem-solving methods in drug addicted and non-addicted soldiers. Journal of Military Medicine, Volume 16, Issue 2, 69-75.

[26] Matinnejad, S. A.; Mousavi, S. A. M.; Shams E., Hasan (1389). Comparing the methods of problem solving and thinking styles in addicts and non-addicts. Journal of Addiction Studies, No. 11, 12-24.

[27] Mcculler $W J$, Sussman $S$, Dent $C W$, Teran $L$. Concurrent prediction of drug use among high-risk youth. Addict Behav. 2001 Jan-Feb; 26 (1): 137-42.

[28] Miller, N. (1995). Addiction psychiatry. New York; US.

[29] Nelson, J. R. (2003). Life skills helping, USA: Books / cole publishing company. New York: W. W. Norton and Company.

[30] Ogden, J. (2000). Health psychology. Bukingham. open university press.
[31] Palahang, H.; Nasrnia, M.; Baraheni, M. N. (1375). An epidemiological study of psychological disorder in Kashan, Journal of thought and behavior, 2 (4), 19-27.

[32] Raisi, F.; Anisi, J.; Yazdi, S. M.; Zamani, M.; Rashidi, S. (1387). Comparison of mental health and parenting practices between addicts and non-addicts, Journal of Behavioral Sciences, 2 (1), 33-41.

[33] Ramesht, M. and Farhad, S. (1383). A study on life skills training in the prevention of substance abuse Students. Second Seminar on mental health.

[34] Saber, F.; Mousavi, S. V.; Salehi, I. (1390). Comparing personality traits of addicted and non-addicted men in problem solving methods, Journal of Research on Addiction, 9 (19), $39-56$.

[35] Sarason, I. G., Johnson. J. H., \& Siegely, M. (1987). Assessing the impact of life changes: development of the life experiences survey. Journal of consulting and clinical psychology. 9, 133146.

[36] Schafer, j. \& brown, a. S. (1997). Marijunna and Cocaen effect expectancies and drug use patterns. Journal of consulting and clinical psychology, vol, 59, 58-69.

[37] Smyth, N. J., \& Washousky. R. C. (1995). The coping styles of alcoholics with Axis II disorders. Journal of Substance Abuse, 7, 425-435.

[38] Shateri Edalat, Z., Ashkani, N., Modarres Ghorori, M., (1388). the relationship between phobic anxiety and problem solving styles and suicide in non-clinical samples, Scientific Journal of Kurdistan University of Medical Sciences, 14 (1), 94-100.

[39] Sobell, M. B. Sobell, L. C. (1997). Problem drinkears guided self-change treatment. New York: Guilford press.

[40] Tylor, S. E. (1995). Health psychology. New York: mc graw hill. 194-200.

[41] Walton, K, E., \& Roberts, B. W. (2004). On the relationship between substance use and personality traits: Abstainccrs are not maladjusted. Journal of Research in Personality, 38, 514535 .

[42] Warren, J. I., Stein, J. A., \& Grella, C. E. (2007). Role of social support and self-efficacy in treatment outcomes among clients with co-occurring disorders. Drug and Alcohol Dependence, 89, 267-274. 